NBER WORKING PAPER SERIES

\title{
REPRESENTATION IS NOT SUFFICIENT FOR SELECTING GENDER DIVERSITY
}

\author{
Justus A. Baron \\ Bernhard Ganglmair \\ Nicola Persico \\ Timothy Simcoe \\ Emanuele Tarantino \\ Working Paper 28649 \\ http://www.nber.org/papers/w28649
NATIONAL BUREAU OF ECONOMIC RESEARCH
1050 Massachusetts Avenue
Cambridge, MA 02138
April 2021

We are grateful to Jari Arkko, Manuel Bagues, Francesca Barigozzi, Graziella Bertocchi, Leslie Daigle, Eliana La Ferrara, Allison Mankin, Kathleen Moriarty, Paola Sapienza, Maria Savona, Leigh Thompson, and Reinhilde Veugelers. We also thank seminar participants at BU (Questrom School of Business), KU Leuven, LUISS, University of Portsmouth, and ZEW (Mannheim) for helpful comments and suggestions, and Laurenz De Rosa for excellent research assistance. Bernhard Ganglmair acknowledges financial support from the Deutsche Forschungsgemeinschaft (DFG, German Research Foundation) through CRC TR 224 (Project B2). The views expressed herein are those of the authors and do not necessarily reflect the views of the National Bureau of Economic Research.

NBER working papers are circulated for discussion and comment purposes. They have not been peer-reviewed or been subject to the review by the NBER Board of Directors that accompanies official NBER publications.

(C) 2021 by Justus A. Baron, Bernhard Ganglmair, Nicola Persico, Timothy Simcoe, and Emanuele Tarantino. All rights reserved. Short sections of text, not to exceed two paragraphs, may be quoted without explicit permission provided that full credit, including (C notice, is given to the source. 
Representation is Not Sufficient for Selecting Gender Diversity

Justus A. Baron, Bernhard Ganglmair, Nicola Persico, Timothy Simcoe, and Emanuele Tarantino NBER Working Paper No. 28649

April 2021

JEL No. D02,J16,J17,M14,O32

\section{ABSTRACT}

Representation of women and minorities in a "selectorate"- the group that chooses an organization's leaders-is a key mechanism for promoting diversity. We show that representation, on its own, is not sufficient for selecting gender diversity: a supportive organizational culture is also required. In the case of the Internet Engineering Task Force, a random increase in female representation in its selection committee caused an increase in female appointments only after cultural norms supporting diversity and inclusion became more salient.

Justus A. Baron

Searle Center on Law

Northwestern University

375 E Chicago Avenue

RB 562

Chicago, ILLI 60611

United States

and Cerna, Mines ParisTech

justus.baron@law.northwestern.edu

Bernhard Ganglmair

ZEW Leibniz Centre for European

Economic Research

L7, 1, 68161

Mannheim, Germany

b.ganglmair@gmail.com

Nicola Persico

Kellogg School of Business

Room 542 Jacobs Center

2001 Sheridan Road

Evanston, IL 60208

and NBER

nicola@nicolapersico.com
Timothy Simcoe

Boston University

Questrom School of Business

595 Commonwealth Avenue

Boston, MA 02215

and NBER

tsimcoe@bu.edu

Emanuele Tarantino

LUISS and EIEF

Viale Romania 32

Roma, Italy

etarantino@gmail.com 


\section{Introduction}

Increasing the representation of women and minorities in "selectorates," i.e., among those who select an organization's leaders, is a key mechanism for promoting diversity. We show that representation in selectorates is not enough: organizational culture as regards diversity must change as well.

This paper is a case study of the determinants of female representation among the leaders of an important standard-setting organization. The Internet Engineering Task Force (IETF) develops inter-operability standards for Internet hardware and software. Without these standards, the Internet would not work. Because the IETF's decisions have enormous technological and financial implications, many companies seek to place employees in leadership roles. Within this context, underrepresentation of women in IETF leadership is highly societally relevant.

The top operational leaders in the IETF are appointed by a selection committee called NomCom. NomCom has ten members who are randomly selected each year from a pool of volunteers. We leverage this random variation to study whether female representation on NomCom causes the committee to appoint more women. The expectation (which is the basis for the random selection procedure) is that equitable female representation within NomCom should ensure equitable female representation among those appointed by NomCom to fill leadership positions.

We find that random increases in female representation in NomCom cause the committee to appoint more women, but only in recent years. During the first half of our study, from 2005 to 2011, more women in NomCom caused fewer women to be appointed. This counterintuitive result echoes some of the most credible findings in the literature, which show that increased female representation in (academic and legal) selection committees does not cause these committees to appoint more women, and sometimes leads to fewer female appointments. We go beyond the prior literature, however, by showing that the sign of the causal relationship flips from negative to positive after some important organizational changes.

We consider several mechanisms that could explain why female representation on NomCom had its intended impact only after 2011. First, we examine changes in the number of female IETF participants and their qualifications. Our findings are essentially unaffected when we control for the "pipeline" of well-qualified women. Next, we ask whether changes in the formal procedures that regulate the appointment process (before and after 2012) might account for the difference. The radical transparency of IETF's procedures ${ }^{1}$ and our interviews with IETF leaders facilitated our task, but we found

\footnotetext{
${ }^{1}$ Similar to a regulatory agency, the IETF publicizes proposed procedural innovations through
} 
no evidence that our results were influenced by any procedural changes. In fact, the interviews suggested a third alternative: changes in IETF "culture" around 2011. By culture, we refer to holistic, informal norms, both societal and organization-specific, i.e., public speeches, codes of conduct, and other activities that are technically unconnected with the appointment process, but whose effect is to change members' attitudes towards certain gender stereotypes. There is strong evidence that IETF culture changed around 2012 because of both active efforts from inside the organization and a broader societal shift in attitudes regarding gender diversity and inclusion in STEM professions. This cultural change, we argue, explains why the relationship between female representation within NomCom and the selection of female IETF leaders switches sign.

In sum, the statistical evidence in this paper establishes a clear regime change: before 2012, a random increase in female representation in NomCom hurts the chances of female appointments; after 2012, it helps them. This evidence indicates that representation is not enough to select gender diversity. Our analysis of the mechanisms suggests that, in our case study, whether or not representation helps diversity is not mediated by the quality of the pipeline, or by the formal procedural rules connected with the appointment process. Instead, the effect of representation is mediated by informal and holistic norms, both societal and organization-specific, some of which are shaped by organizational leadership.

\section{Hypotheses and related literature}

There is broad support for the idea that representation in a collective decision-making body helps protect a group's interests. Variation in the composition of the political franchise, for example, has been shown to impact a variety of policies ${ }^{2}$ with some papers focusing specifically on the gender composition of the franchise and showing that policies change in the expected directions.$^{3}$ Similarly, variation in the representation of Blacks in criminal juries has been shown to influence jury verdicts in the expected direction. ${ }^{4}$

The benefits of representation are less straightforward when the decision-making body is an organizational committee whose members are bound by a common set of professional norms, because these norms often play an important mediating role. We focus on the gender composition of selectorates, i.e., groups or committees that select other individuals for leadership positions. These include boards of directors, promotion committees, and selection panels (but not criminal juries).5 Relative to other decision making bodies,

\footnotetext{
"Internet Drafts" which undergo a "public comment period," and then all accepted changes are enshrined into IETF's technical standards and organizational practices, or RFCs (from "Request for Comments").

2 Berlinski and Coppenolle (2014), Corvalan et al. 2020), Larcinese (2014).

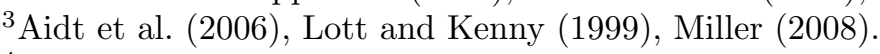

4 Anwar et al. (2012).

${ }^{5}$ Criminal juries do not engage in selecting one among many candidates, but rather on a single
} 
talent availability is of primary importance to selectorates.

Most academic studies lack access to random variation in the selectorate's gender composition, leading to well-known concerns about the impact of (possibly unobserved) confounds ${ }^{6}$ There are, however, a few studies that exploit random selection into a selectorate for casual inference: Bagues and Esteve-Volart (2010) in the context of Spanish judges and Bagues et al. (2017) in the context of university professors. These authors find, counterintuitively, that a random increase in the percentage of women on a selection committee does not increase (and, for Spanish judges, decreases) the likelihood that women are appointed. The decrease found by Bagues and Esteve-Volart (2010) is tentatively attributed to female evaluators' bias in favor of male candidates. A third causal study by De Paola and Scoppa (2015) finds the opposite result: more women in the selection committee cause more women to be appointed professor. We reconcile these divergent findings by proposing that organizational culture moderates the impact of representation. This is the first paper where random variation in representation is shown to have either a positive or a negative causal effect. Among the causal studies, our work is also unique for its focus on STEM workers, as opposed to academics or judges. This focus is important in light of broader societal concerns regarding women's representation in STEM fields.

From the prior literature, we draw three broad and mutually exclusive hypotheses:

\section{$H_{0}$ : Greater female representation in a selection committee leads to more} women being selected. Hypothesis $H_{0}$ is the expected direction of the relationship. This is why selection committees are designed to be representative in their composition (which, incidentally, might be why the NomCom formation process is based so explicitly on random selection). Among the causal studies cited above, De Paola and Scoppa (2015) support this hypothesis. Related (but not focused on gender) studies support the idea that changing the characteristics of the "political selectorate" has an impact on who is selected $]^{7}$ and that a random increase in the fraction of Blacks empaneled in a jury decreases the likelihood that Black defendants are convicted 8

\section{$H_{1}$ : Greater female representation in a selection committee leads to the same,} or fewer women being selected. Hypothesis $H_{1}$ is less intuitive, but it is the takeaway

"candidate." As such, issues such as "talent availability" are not applicable.

6 Bertrand et al. (2019), Delgado-Pina et al. (2020), Gould et al. (2018a b), Kunze and Miller (2017), Maida and Weber (2020), Matsa and Miller (2011).

'Corvalan et al. (2020) show that eliminating suffrage restrictions in the U.S. sizably decreased the wealth of those elected.

8 Anwar et al. (2012). 
from the two largest and most credible studies in the existing literature ${ }^{9} 10$ Bagues and Esteve-Volart (2010), who find that fewer women are selected, speculate that this effect might either be due to a female "inferiority complex" in regards to men, or to a stronger "rally around the male flag" behavior on the men's part when more women are present in the committee. The authors, however, provide no direct evidence with respect to these proposed mechanisms. An alternative "signaling" hypothesis has that women take the personally costly action of not promoting their peers to signal their commitment to other values, such as technical excellence in the case of the IETF.

$\mathrm{H}_{2}$ : The relationship between female representation in a selection committee and the gender of selected individuals is moderated by norms (both internal and external to the organization). Hypothesis $H_{2}$ holds that for representation to matter, informal norms must be supportive of diversity and inclusion. This theory reconciles the conflicting evidence from prior studies, because it implies that diverse representation in a selectorate may or may not translate into diverse appointments.

\section{IETF's formal institutions}

IETF in general. The IETF is the main forum for internet protocol development. It is responsible for setting internet standards, including well known ones such as HTTP, POP3, and FTP. Put simply, the hardware that makes the internet possible would not work if it deviated from IETF-defined protocols 11

The IETF is an open community and anyone can participate. Participants are corporate employees, academics, engineers, and computer scientists. Participants offer input in the setting of standards. They do so by sharing technical information within a working group that, collectively, is responsible for creating a draft specification that may or may not evolve into a new standard. Working groups are organized by topic into broad technical areas (currently seven, including: Routing, Transport, Security, etc.). For example, the HTTP standard was initially developed by the "HTTP working group" which was part of the "Applications and Real-Time" area. Working Groups are chartered to write RFCs (for "Request for Comments") that describe the IETF's technical standards and organizational practices. Each working group must reach a consensus on the contents of an RFC before it is published.

\footnotetext{
${ }^{9}$ These are Bagues and Esteve-Volart (2010) and Bagues et al. (2017). The latter is similar to De Paola and Scoppa (2015) in that both look at candidates for university posts, but Bagues et al. (2017) include 100 times the number of candidates in their sample.

${ }^{10}$ Among the non-causal papers, Berlinski and Coppenolle (2014) and Larcinese (2014) find no "selectorate effect" in political representation.

${ }^{11}$ See Table A.I for notable examples of technological standards developed by the IETF.
} 
Two powerful appointed positions: ADs and IAB members. Every area is headed up by an area director (AD). The $\mathrm{AD}$ is a technical expert with knowledge broad enough to oversee several working groups in her/his area. The AD is responsible for the productivity of these working groups ${ }^{12}$ When a working group produces a draft about which the AD is able to create sufficient "community consensus" (including from other ADs), the draft is elevated and tracked to become a standard. The AD can charter new working groups and disband old ones. ADs are appointed for two years. Not surprisingly, ADs are viewed as powerful:

"[M] any people look at the ADs as somewhat godlike creatures." 13

IAB members are also powerful. Compared to ADs they are less technical wizards, and more "wise (wo)men." The IAB is composed of twelve members who serve for two years. Their mandate is as follows:

"The IAB is responsible for keeping an eye on the 'big picture' of the Internet. [...] IAB members pay special attention to emerging activities in the IETF. When a new IETF Working Group is proposed, the IAB reviews its charter for architectural consistency and integrity." 14

ADs and IAB members are appointed by a nominating committee (colloquially, NomCom). We refer to individuals in these two positions as "NomCom appointees."

The selection committee (NomCom). NomCom is composed of a (non-voting) chair and ten members. NomCom's task is to nominate the ADs and the IAB members "based on its understanding of the IETF community's consensus of the qualifications required to fill the open positions." 15 In practice, NomCom members collect proposals for nominations and feedback from the community and then interview the candidates for the open positions. They then vote to select the appointees using a voting mechanism that is proposed by the chair 16 The individuals nominated by NomCom must undergo a review process before being appointed, but the process is pro-forma, so henceforth we will make no distinction between "nominees" and "appointees."17 NomComs are formed

\footnotetext{
${ }^{12}$ Huizer and Crocker (1994, p. 17).

13 Hoffman and Harris $(2006$, p. 9).

${ }^{14} \overline{\text { Hoffman and Harris }}\left(\frac{2019}{20}\right.$, section 2.2 .3$)$.

15 Galvin (2004, p. 7).

${ }^{16}$ See Galvin (2004, p. 17). To our knowledge, the voting mechanisms are not made public.

${ }^{17}$ Technically, NomCom only has the power to recommend, not to appoint. Once NomCom has recommended candidates for the open positions, the candidates are reviewed and confirmed by another body. In practice, however, confirmation is a mere formality.
} 
in the second half of a given year $t$ (formation year), and they make appointments in the following year $t+1$ (operation year).

NomCom members are simultaneously selected from a volunteer pool and serve for approximately one year. Anyone who has attended at least 3 out of the 5 previous (tri-annual) IETF meetings can volunteer. In 2019, for example, there were 177 volunteers for 10 NomCom positions. Similar to serving as an AD or IAB member, NomCom membership implies a significant time commitment. Volunteering for NomCom signals that an individual and their employer are willing to commit the necessary time.

A random-number generator algorithm is used to draw members from the NomCom volunteer pool. ${ }^{18}$ For example, in 2019 the algorithm ranked volunteers using the outcomes of three public lotteries and a baseball game as "seeds," and the ten top-ranked volunteers (by the random-number generator) became NomCom members.19 We use this random variation in the selection of NomCom members to estimate the causal impact of gender composition in the selectorate.

\section{Societal and informal norms change around 2011-12}

At a societal level, the issue of gender diversity in STEM disciplines became of acute concern around 2011-12. Figure 1 illustrates this shift using data from Google searches, plotting the ratio of gender-gap STEM-related searches to all STEM-related searches on a monthly basis from 2004 through 2020 .

Concurrently, IETF's ecosystem was also changing, a sentiment expressed by Kathleen Moriarty, a former AD and an IETF leader in diversity issues:

"Many companies were making an internal push for greater diversity, and that was imported to IETF via participants. Other standards consortia were experiencing similar issues.' 20

Within IETF, meanwhile, things appeared to be at odds with evolving societal attitudes. The NomComs operating in years 2009, 2010, and 2012 did not appoint a

\footnotetext{
${ }^{18}$ The algorithm is detailed in in RFC 2777 (Eastlake, 2004).

${ }^{19}$ The actual seeds used in 2019 were the numbers of the EuroMillions Lottery (July 5, 2019), statistics of the Orioles vs. Blue Jays baseball game (July 5, 2019), the numbers of the Ontario Lottery (July 6, 2019), and US Power Ball lottery (July 5, 2019). See https://datatracker.ietf.org/nomcom/ann/ 110997 (last accessed: February 4, 2021).

${ }^{20}$ Kathleen Moriarty (former AD), personal communication (July 17, 2020). Similarly, Leslie Daigle (former IAB chair), personal communication (June 18, 2020): "Corporatization of IETF may have induced the push for diversity: managers care more about diversity, due to HR policies, than academics."
} 

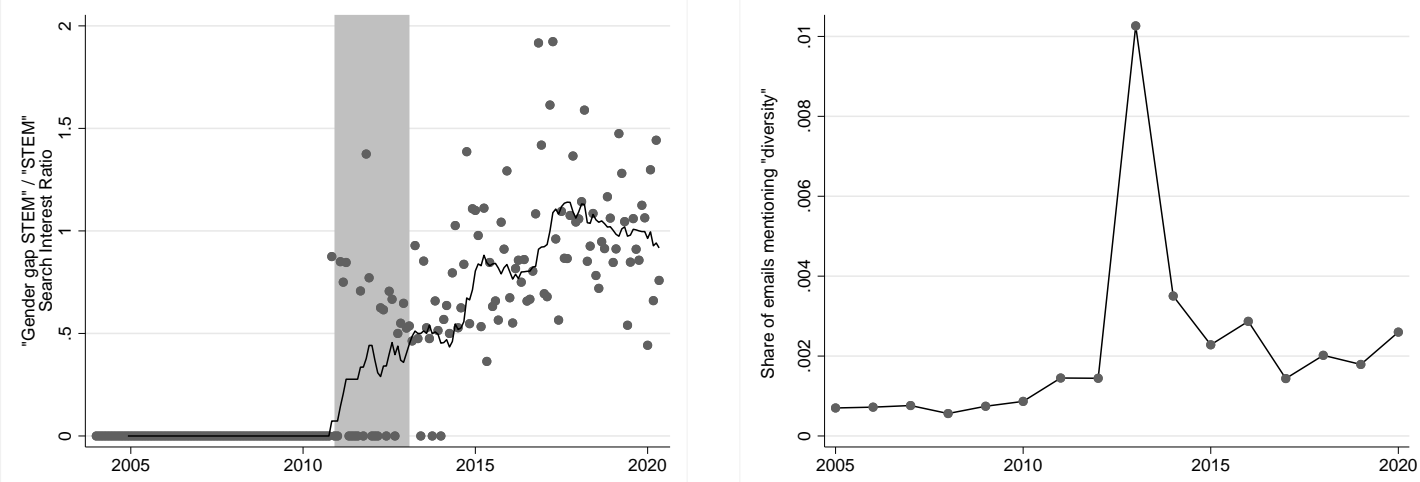

Figure 1: Societal norms (left panel) and informal norms (right panel) change in calendar year 2011-12. In the left panel, each point corresponds to the monthly ratio of the search-interest value for "gender gap STEM" to the search-interest value of "STEM." The solid line is a 12 month trailing average, and the shaded area covers calendar years 2011-12. Source: Google Trends. In the right panel, the vertical axis is the share of individual emails posted on all IETF mailing lists that contain the term "diversity." The horizontal axis is a calendar year.

single woman. Some inflammatory events in 2011-12 are referred to only obliquely in internal IETF reports that describe a historical culture of "white, male technicians, demonstrating a distinctive and challenging group dynamic." 212 Finally, in calendar year 2012, an IETF affinity group called "Systers" created an experiment of sorts: they quietly transmitted to the 2013 NomCom a slate of many qualified female candidates for appointment to ADs. NomCom appointed none of them ${ }^{22}$ These events generated a perception that random selection of NomCom members was not working as expected. Specifically, women were not being appointed at a rate commensurate with their presence in the eligible pool.

The earliest institutional response we could trace goes back to 2012, when a "Diversity Design Team" (DDT) was established ${ }^{23}$ In April 2013, the IETF chair wrote a blogpost titled "Diversity" where he announced the creation of the DDT and foreshadowed a mentoring initiative ${ }^{24}$ In the same month, a diversity mailing list was set up to create a forum for discussion. In 2013, the share of emails containing the word "diversity" shot up to an all-time high of $1 \%$ of all IETF emails (see Figure 1). Based on this measure, discussion of diversity was already increasing by 2011, and after 2013 it stabilized around

\footnotetext{
${ }^{21}$ See RFC 7704 (Crocker and Clark, 2015) and https://www.ietf.org/blog/ ietf-diversity-update (last accessed: February 4, 2021).

${ }^{22}$ Our data confirm that no female AD, and only one female IAB member unconnected with the Systers experiment, was appointed in 2013. The experiment was later spotlighted by the online publication Vice.com as "a pretty clear case of systemic bias" (Turk, 2015).

23 Moriarty and Arkko (2015) write: "In 2012, when these behavior and diversity issues were glaringly apparent to the IETF, Jari Arkko worked with others to establish a 'Diversity Design Team'.” Jari Arkko was an AD in 2012, and later became chair of IETF.

24 Arkko (2013). Moriarty and Arkko (2015) report that the mentoring program was later established. The program sought to assist newcomers, who are more likely to be female relative to legacy members.
} 
$0.2 \%$ of all IETF emails (more than twice the pre-2010 average).

The DDT reported out in an IETF plenary session in July 2013 and recommended, among other changes, that a code of conduct be adopted and that more diverse ADs and working group chairs be selected 25 In November 2013, the ADs collectively posted a statement titled "IETF Anti-Harassment Policy." 26 In early 2014, two draft RFCs were posted: one proposing anti-harassment procedures ${ }^{27}$ the other discussing practical ways to boost diverse participation in IETF ${ }^{28}$ Finally, the 2014 NomCom chair adopted "equitable" as opposed to "rapid" shortlisting procedures, and inclusive interviewing for her NomCom only ${ }^{29}$ The changes worked. By 2015, Moriarty was able to report:

"In short, I think we've come a long way since 2012. We do have more work to do and still have some issues, but there is a very quick and open dialog that typically follows any occurrence of inappropriate conduct now.' 30

This section described the triggers, both societal and internal to IETF, that made gender diversity a hot topic within IETF, and how IETF responded. The story is that society changed, and the IETF found that its formal institutions of representation (NomCom) did not deliver the desired effect. Change was imperative. The change in IETF was promoted from the top and, critically for our interpretation, it was not a change to the formal mechanism and procedures of NomCom but, rather, a push to adopt more inclusive informal norms and attitudes. In the rest of the paper, we show that these changes successfully activated the formal institution of representation to work as intended.

\section{Data description}

For every calendar year between 2005 and 2020, we collected data including the name of each IETF meeting attendee, NomCom volunteer, NomCom member, and appointee

\footnotetext{
${ }^{25}$ The DDT's agenda is available at https://www.ietf.org/proceedings/87/slides/ slides-87-iesg-opsplenary-8.pdf (last accessed: March 25, 2021).

${ }^{20}$ See https://www.ietf.org/about/groups/iesg/statements/anti-harassment-policy, posted on November 3, 2013 (last accessed: February 4, 2021).

${ }^{27}$ The first draft of RFC 7776 (Resnick and Farrel, 2016) was published in February 2014. The final version was published in March 2016.

${ }^{28}$ The first draft of RFC 7704 (Crocker and Clark, 2015) was published in March 2014. The final version was published in November 2015.

${ }^{29}$ Allison Mankin, personal communication (August 7, 2020). We do not include these changes in NomCom's nomination procedure as part of our proposed mechanism and, indeed, regard them as a potential confounder of the "cultural change" channel. Thus, although 2014 happens to be a "peak female" appointment year (see Figure 2), we conduct several tests to ensure that our main findings are not an artifact of that year's outcomes.

${ }^{30}$ Turk (2015).
} 
(IAB member or AD) ${ }^{31}$ Gender was not recorded and so had to be imputed. To minimize subjective judgment calls, we used a script called "genderizeR" that assigns a probability to each name. ${ }^{32}$ This approach measures how appointees are perceived by others, which may differ from how they self-identify or from their assigned sex at birth. The data contain 13 appointments per year, on average, and each NomCom has ten members, with the number of female members varying between zero and two ${ }^{33}$ We construct two samples for analysis. The first sample consists of all NomCom appointees $(N=209)$. The second sample contains one observation for each IETF participant-year $(N=307,210)$, where a participant is anyone who has attended an IETF meeting, authored a draft specification, or emailed an IETF listserv.

This paper asks whether female representation in NomCom causes more female appointees, and Figure 2 illustrates our main result. The left panel of Figure 2 shows that the share of female appointees declined prior to the shift in informal norms, actually reaching zero in 2009, 2010, and 2012, before increasing sharply thereafter. The right panel of Figure 2 shows the relationship between female NomCom representation and female appointment rates: decreasing before 2012 and increasing afterwards.
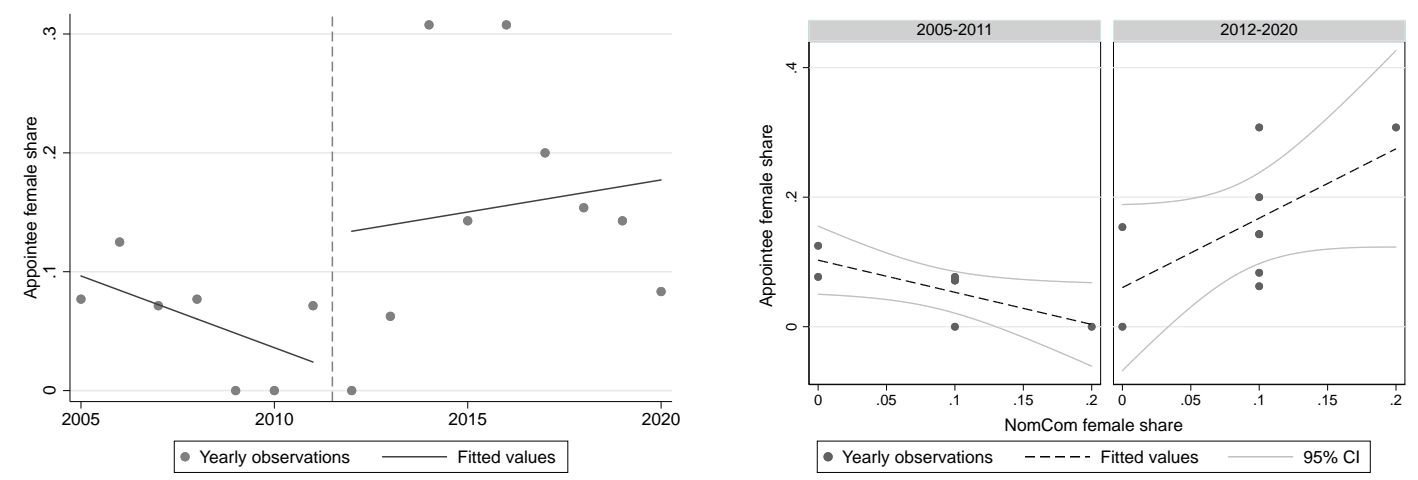

Figure 2: Before 2012, greater female representation in NomCom did not translate in more women appointed; after 2012 norm shift, it did. In the left panel, the horizontal axis is NomCom year, which coincides with the calendar year in which a given NomCom makes appointments. The vertical axis is the share of women among all appointees in a given year. In the right panel, horizontal axes depict female representation in a NomCom. Vertical axes depict the share of appointments by that NomCom that are female. The straight lines are best linear fits. The slopes have opposite signs before and after calendar year 2012, suggesting a different direction in the relationship before and after 2012.

Neither figure adjusts for the number of women at risk of appointment. If each

\footnotetext{
${ }^{31}$ The information was downloaded from IETF's website https://ietf.org. We drop the years 2003 and 2004 because information on volunteers is incomplete.

${ }^{32}$ The "genderizeR" script is described in Wais (2016). We corroborated the results using "he/she" statements and profile pictures on the bio pages of NomCom volunteers, NomCom members, and appointees.

${ }^{33}$ Summary statistics for NomCom members and volunteers are in Table A.II
} 
NomCom draws from a large pool of well-qualified male and female candidates, as suggested by the Systers' 2012 experiment, one might reasonably assume that no adjustment is necessary. On the other hand, we might want to control for the relative quality of male and female "appointables" given that female IETF participation has increased over time (albeit, not very quickly).34 The next sections present statistical evidence supporting the hypothesis that informal norms are required to activate the effects of representation.

\section{Female representation in NomCom causes a decrease in female appointments before the 2012 norm shift, and an increase thereafter}

Our first set of regressions takes the IESG/IAB appointee as the unit-of-analysis. The outcome variable is an indicator variable that equals one if the appointee is coded as female and zero otherwise. The key explanatory variables are the share of female NomCom members and an indicator for years 2012 and later, where the latter serves as a proxy for the change in informal norms. Our model is specified as:

$$
\begin{aligned}
\text { Female }_{i t}= & \alpha+\text { Pre }_{t} \cdot\left(\beta_{\text {pre }} \text { NomComp }_{t}+\gamma_{\text {pre }} X_{t}\right)+ \\
& \text { Post }_{t} \cdot\left(\beta_{\text {post }} \text { NomComp }_{t}+\gamma_{\text {post }} X_{t}\right)+\epsilon_{i t},
\end{aligned}
$$

where Female $_{i t}$ codes the gender of the person $i$ appointed in year $t$; NomComp N $_{t}$ is the share of women in the NomCom that operates in year $t$ (which was formed at $t-1$ ); Pre $_{t}$ and Post $_{t}$ are indicators for the period before and after the 2012 norm shift; $X_{t}$ measures the share of females in the population at-risk of appointment; and $\epsilon_{i t}$ is an econometric error term. We set Female $_{i t}$ equal to one whenever genderizeR returns a probability greater than $75 \%$ that person $i$ 's name is associated with a woman ${ }^{35}$

Because the shortlists created by each NomCom are confidential, we cannot observe how many women are considered in each year. Instead, we set $X_{t}$ equal to the share of females in the NomCom volunteer pool ${ }^{36}$ In addition to serving as a proxy for the pool

\footnotetext{
${ }^{34}$ See Appendix Table A.XI along with Figures A.2 and A.3. showing that female participation in IETF and the share of women in the pool of NomCom volunteers increased between 2005 and 2020.

${ }^{35}$ The results are robust to varying this threshold. At the $75 \%$ cutoff, about $89 \%$ of NomCom volunteers and $92 \%$ of NomCom members could be assigned a gender. The rest are excluded from the sample. However, we report the results of regressions obtained using the raw probabilities from genderize $R$ to impute the sex of individuals (see Tables A.IV and A.VIII).

${ }^{36}$ We choose the year in which NomCom was formed, as opposed to the year in which it made appointments, because most appointments are made early in the calendar year, before volunteers for the next NomCom are solicited.
} 
of appointable women, this guarantees that $N_{o m C o m p}$ is uncorrelated with $\epsilon_{i t}$, because of the random selection process (i.e., each NomCom is formed by a random draw from a population with a fraction $X_{t}$ of women).

We estimate Equation (1) by ordinary least squares regression, and cluster standard errors at the year level because outcomes may not be independent within a NomCom year ${ }^{37}$ The coefficients of interest are the $\beta$ 's, which measure the relationship between female NomCom representation and the probability of female IESG/IAB appointees before and after the shift in informal norms. Estimates are reported in Table I.

\begin{tabular}{|c|c|c|c|c|}
\hline $\begin{array}{l}\text { Specification } \\
\text { Unit of Analysis }\end{array}$ & & NomCo & $\begin{array}{l}\mathrm{LS} \\
\text { Appointee }\end{array}$ & \\
\hline Outcome Variable & (1) & $\begin{array}{c}\text { 1[Appoin } \\
(2)\end{array}$ & $\begin{array}{l}\text { e is Female] } \\
(3)\end{array}$ & (4) \\
\hline Pre $\times$ NomCom Female Share & $\begin{array}{c}0.39 \\
{[0.47]}\end{array}$ & $\begin{array}{c}-0.50 \\
{[0.15]^{* * *}}\end{array}$ & $\begin{array}{c}-0.62 \\
{[0.19]^{* * *}}\end{array}$ & $\begin{array}{l}-0.24 \\
{[0.21]}\end{array}$ \\
\hline Post $\times$ NomCom Female Share & & $\begin{array}{c}1.08 \\
{[0.38]^{* *}}\end{array}$ & $\begin{array}{c}1.19 \\
{[0.24]^{* * *}}\end{array}$ & $\begin{array}{c}0.99 \\
{[0.35]^{* *}}\end{array}$ \\
\hline Pre $\times$ Volunteer Female Share & $\begin{array}{c}0.58 \\
{[1.06]}\end{array}$ & & $\begin{array}{c}0.84 \\
{[0.56]}\end{array}$ & $\begin{array}{l}-0.70 \\
{[0.77]}\end{array}$ \\
\hline Post $\times$ Volunteer Female Share & & & $\begin{array}{l}-2.07 \\
{[1.11]^{*}}\end{array}$ & $\begin{array}{l}-1.76 \\
{[1.37]}\end{array}$ \\
\hline Post & & $\begin{array}{l}-0.04 \\
{[0.05]}\end{array}$ & $\begin{array}{c}0.20 \\
{[0.11]}\end{array}$ & $\begin{array}{c}0.13 \\
{[0.12]}\end{array}$ \\
\hline $\mathrm{N}$ & 209 & 209 & 209 & 209 \\
\hline R-squared & 0.01 & 0.04 & 0.05 & 0.05 \\
\hline
\end{tabular}

Table I: Effect of NomCom gender composition on appointee gender is negative before the 2012 informal norm shift, positive thereafter. In all columns, Female $e_{i t}$ is 1 if probability that appointee $i$ is female exceeds $75 \%$, and $N o m C o m p_{t}$ (resp., $X_{t}$ ) is the average of the "female dummies" among NomCom members (resp., volunteers). Post $t_{t}=1[$ Year $\geq 2012]$ for models (1) to (3); and $1[$ Year $\geq 2013]$ for model (4). Stars indicate significance at $* 10 \%$, $* * 5 \%$ and $* * * 1 \%$ level. Standard errors clustered by year.

Model (1) fixes $\beta_{\text {pre }}=\beta_{\text {post }}$ and $\gamma_{\text {pre }}=\gamma_{\text {post }}$ in order to estimate a single NomCom representation effect for the entire study-period. The point estimate for $\beta$ is positive and implies that adding one female to NomCom (a 10 percent increase) is associated with a 3.9 percentage point increase in female appointments. But the relationship is not statistically significant at conventional levels. This null result is summarized in the title

\footnotetext{
${ }^{37}$ OLS estimates provide an easy to interpret summary of the conditional probabilities, and are generally quite close to the average marginal effects from a logistic regression (see Tables A.V and A.IX). The results are robust to using alternative specifications (i.e. logit) more commonly applied to binary outcomes.
} 
of the paper: representation is not sufficient for selecting gender diversity. Model (2) estimates the pre- and post-period $\beta$ 's without any controls (making it directly comparable to the right panel of Figure 2). The results show that $\hat{\beta}_{\text {pre }}<0<\hat{\beta}_{\text {post }}$ with both inequalities statistically significant: the correlation between female NomCom representation and female appointments is negative before 2012, and positive after.

Model (3) adds the share of women in the volunteer pool as a control. Based on these estimates, the causal effect of adding a woman to NomCom after the shift in informal norms is an 11.9 percentage point increase in female IAB/IESG appointments, compared to a 6.2 percentage point decrease beforehand ${ }^{38}$ This is our preferred specification, and it provides strong evidence in support of $\mathrm{H} 2$. While the coefficients on the share of volunteers in model (3) are not statistically different from zero, the point estimate for $\gamma_{\text {post }}$ is negative. Because the share of female volunteers declines after NomCom 2011 (see Figure A.2, this indicates that the number of female appointees grew even while the share of "female appointables" declined, providing additional support for our regime change assumption.

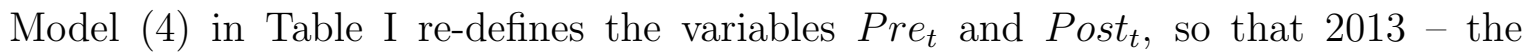
NomCom of the Systers' experiment - is included in the pre-period. Although the basic pattern of results does not change, we no longer find the negative impact of female NomCom representation in the pre-period is statistically significant. Additional robustness checks are in the Appendix ${ }^{39}$

\section{Alternative mechanisms}

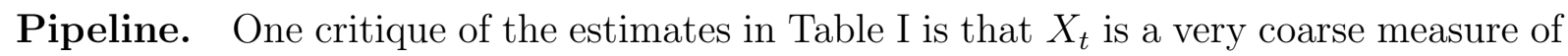
the relative quality of female IETF participants. This might be a concern if the availability of qualified female candidates increased over time. To address this issue, we estimate a second set of models that include individual-level measures of IETF engagement and leadership. For this analysis, we turn to the larger sample of all IETF participant-years, where each individual enters the panel in the first year they are observed in any IETF

\footnotetext{
${ }^{38} \mathrm{We}$ obtain very similar estimates from models where we constrain $\beta_{j}=\gamma_{j}$ for $j \in\{$ pre, post $\}$, which is equivalent to using the de-trended explanatory variable $\Delta$ Female $\equiv$ NomCom Female Share Volunteer Female Share. See Appendix Table A.VI.

${ }^{39}$ Tables A.III and A.VII show that the results are robust to excluding IAB appointments. This is a useful check because, based on our conversations with IETF former ADs, IAB members are often treated by NomCom as a slate, as opposed to the ADs who are voted on position-by-position.
} 
dataset. Our model is specified as:

$$
\begin{aligned}
\text { Appointed }_{i t}= & \alpha+\text { Pre }_{t} \cdot\left(\beta_{\text {pre }} \text { NomComp }_{t} \cdot \text { Female }_{i}+\gamma_{\text {pre }} \text { Female }_{i}\right)+ \\
& \text { Post }_{t} \cdot\left(\beta_{\text {post }} \text { NomComp }_{t} \cdot \text { Female }_{i}+\gamma_{\text {post }} \text { Female }_{i}\right)+ \\
& \theta \text { Quality }_{i t}+\lambda_{t}+\epsilon_{i t},
\end{aligned}
$$

where the outcome Appointed At $_{i}$ is an indicator equal to 100 if person $i$ is appointed to IESG or IAB in year $t$ and zero otherwise. The variables Pre ${ }_{t}$, Post $_{t}$, and NomComp are defined above, and Female Fe $_{i}$ is andicator equal to one if genderizeR assigns a $75 \%$ or greater probability that a name is female. The vector Quality ${ }_{i t}$ contains several measures of individual IETF engagement and leadership described below, and $\lambda_{t}$ is a vector of calendar-year effects.

Equation (2) is a triple-differences specification where the main effects of $\mathrm{NomComp}_{t}, \mathrm{Pre}_{t}$, and Post $t$, along with all of their two-way interactions, are absorbed by the calendar-year fixed effects. Once again, the coefficients of interest are $\beta_{\text {pre }}$ and $\beta_{\text {post }}$, which measure the association between female NomCom representation and the probability that a woman is appointed to IESG or IAB before and after the shift in norms. Estimates are reported in Table II.

Models (1) and (2) parallel the first two columns of Table II. Without accounting for the regime change, we estimate a positive and statistically insignificant relationship between female representation and female appointments. After accounting for the norm shift, we obtain $\hat{\beta}_{\text {pre }}<0<\hat{\beta}_{\text {post }}$ with both inequalities statistically significant. Model (3) adds the stock of published RFCs, the number of emails sent to IETF listservs, and the number of IETF meetings attended by individual $i$ as controls. ${ }^{40}$ Each of these proxies for individual IETF engagement is highly statistically significant, but collectively they produce no measurable change in the parameters of interest. Model (4) adds the control variable Incumbent ${ }_{i t}$, which equals one if individual $i$ served as an $\mathrm{AD}$ or IAB member in any year prior to $t$, along with a set of dummies indicating how many times individual $i$ has previously served as a WG chair (top-coded at four). Adding these proxies for IETF leadership substantially increases the overall model R-squared, and produces large changes in the coefficient estimates for the other measures of individual IETF engagement. It does not, however, change the estimates of $\beta_{\text {pre }}$ or $\beta_{\text {post }}$. Finally, model (5) redefines Pre $_{t}$ and Post $t_{t}$ by assuming the shift in norms occurs one year later, retaining all of the individual controls, and obtains estimates very similar to model (4) in Table I.

Overall, the regression analyses confirm the visual pattern in Figure 2 (right panel):

\footnotetext{
${ }^{40}$ Because all of these variables are highly skewed, we take natural logs (after adding one) before including them as regressors.
} 


\begin{tabular}{|c|c|c|c|c|c|}
\hline \multirow{2}{*}{$\begin{array}{l}\text { Specification } \\
\text { Unit of Analysis } \\
\text { Outcome Variable }\end{array}$} & \multicolumn{5}{|c|}{$\begin{array}{c}\text { OLS } \\
\text { IETF Participant-Year }\end{array}$} \\
\hline & (1) & $\begin{array}{l}\text { Appointec } \\
(2)\end{array}$ & $\begin{array}{l}\text { to IESG } \\
(3)\end{array}$ & $\underset{(4)}{\operatorname{IAB}]} \times 1$ & 00 \\
\hline Pre $\times$ Female $\times$ NomCom Share & $\begin{array}{c}0.30 \\
{[0.30]}\end{array}$ & $\begin{array}{c}-0.29 \\
{[0.14]^{* *}}\end{array}$ & $\begin{array}{l}-0.26 \\
{[0.13]^{*}}\end{array}$ & $\begin{array}{c}-0.22 \\
{[0.11]^{*}}\end{array}$ & $\begin{array}{l}-0.06 \\
{[0.15]}\end{array}$ \\
\hline Post $\times$ Female $\times$ NomCom Share & & $\begin{array}{c}0.71 \\
{[0.26]^{* *}}\end{array}$ & $\begin{array}{c}0.71 \\
{[0.27]^{* *}}\end{array}$ & $\begin{array}{c}0.72 \\
{[0.21]^{* * *}}\end{array}$ & $\begin{array}{c}0.57 \\
{[0.20]^{* *}}\end{array}$ \\
\hline Pre $\times$ Female & $\begin{array}{l}-0.01 \\
{[0.03]}\end{array}$ & $\begin{array}{l}-0.00 \\
{[0.02]}\end{array}$ & $\begin{array}{c}0.02 \\
{[0.02]}\end{array}$ & $\begin{array}{c}0.01 \\
{[0.02]}\end{array}$ & $\begin{array}{l}-0.02 \\
{[0.02]}\end{array}$ \\
\hline Post $\times$ Female & & $\begin{array}{l}-0.03 \\
{[0.03]}\end{array}$ & $\begin{array}{c}0.01 \\
{[0.03]}\end{array}$ & $\begin{array}{l}-0.02 \\
{[0.03]}\end{array}$ & $\begin{array}{l}-0.00 \\
{[0.03]}\end{array}$ \\
\hline $\ln (1+\mathrm{RFCs})$ & & & $\begin{array}{c}0.39 \\
{[0.05]^{* * *}}\end{array}$ & $\begin{array}{c}0.05 \\
{[0.04]}\end{array}$ & $\begin{array}{c}0.05 \\
{[0.04]}\end{array}$ \\
\hline $\ln (1+$ Emails $)$ & & & $\begin{array}{c}0.07 \\
{[0.01]^{* * *}}\end{array}$ & $\begin{array}{c}0.02 \\
{[0.01]^{* *}}\end{array}$ & $\begin{array}{c}0.02 \\
{[0.01]^{* *}}\end{array}$ \\
\hline $\ln (1+$ Meetings $)$ & & & $\begin{array}{c}0.07 \\
{[0.01]^{* * *}}\end{array}$ & $\begin{array}{c}0.03 \\
{[0.01]^{* * *}}\end{array}$ & $\begin{array}{c}0.03 \\
{[0.01]^{* * *}}\end{array}$ \\
\hline Incumbent & & & & $\begin{array}{c}0.58 \\
{[0.08]^{* * *}}\end{array}$ & $\begin{array}{c}0.58 \\
{[0.08]^{* * *}}\end{array}$ \\
\hline $\begin{array}{l}\text { WG Chair Experience Effects } \\
\text { Year Fixed Effects }\end{array}$ & $\checkmark$ & $\checkmark$ & $\checkmark$ & $\begin{array}{l}\checkmark \\
\checkmark\end{array}$ & $\begin{array}{l}\checkmark \\
\checkmark\end{array}$ \\
\hline $\begin{array}{l}\mathrm{N} \\
\mathrm{R} \text {-squared }\end{array}$ & $\begin{array}{c}307,210 \\
0.00\end{array}$ & $\begin{array}{c}307,210 \\
0.00\end{array}$ & $\begin{array}{c}307,210 \\
0.01\end{array}$ & $\begin{array}{c}307,210 \\
0.04\end{array}$ & $\begin{array}{c}307,210 \\
0.04\end{array}$ \\
\hline
\end{tabular}

Table II: Effect of NomCom gender composition on appointments controlling for individual experience. In all columns Female $_{i}$ is 1 if probability that individual $i$ is female exceeds $75 \%$, and NomComp $p_{t}$ is the average of the "female dummies" among NomCom members. Post $_{t}=1[$ Y ear $\geq 2012]$ for models (1) to (3); and 1[Year $\left.\geq 2013\right]$ for model (4). Stars indicate significance at $* 10 \%, * * 5 \%$ and $* * * 1 \%$ level. Standard errors clustered by year.

a random increase in female representation in NomCom produces an increase in female appointees after, and only after, the change in IETF's informal norms.

Procedural changes. The IETF is characterized by radical transparency, and our investigation of NomCom's formal procedures revealed no major changes during the sample period, with the possible exception of 2014. During our interview with Allison Mankin, the chair of the 2014 NomCom, we were informed that she adopted gender-blind shortlisting for that year's appointees, as well as inclusive interviewing procedures. To address any concern that this outlier NomCom is driving the results, we re-estimate Equation (1) for a subsample that excludes the appointments made in 2014. 
Table III shows that our main results are unchanged. ${ }^{41}$

\begin{tabular}{lcccc}
\hline \hline Specification & \multicolumn{4}{c}{ OLS } \\
Unit of Analysis & \multicolumn{4}{c}{ NomCom Appointee } \\
Outcome Variable & $(1)$ & $(2)$ & $(3)$ & $(4)$ \\
& & & & \\
& & & \\
& & & \\
Pre $\times$ NomCom Female Share & 0.40 & -0.50 & -0.62 & -0.24 \\
& {$[0.48]$} & {$[0.15]^{* * *}$} & {$[0.19]^{* * *}$} & {$[0.21]$} \\
Post $\times$ NomCom Female Share & & 1.02 & 1.16 & 1.12 \\
& & {$[0.43]^{* *}$} & {$[0.29]^{* * *}$} & {$[0.43]^{* *}$} \\
Pre $\times$ Volunteer Female Share & 0.04 & & 0.84 & -0.70 \\
& {$[0.86]$} & & {$[0.56]$} & {$[0.77]$} \\
Post $\times$ Volunteer Female Share & & & -2.90 & -2.83 \\
& & & {$[0.56]^{* * *}$} & {$[0.51]^{* * *}$} \\
Post & & -0.05 & 0.26 & 0.20 \\
& & {$[0.05]$} & {$[0.09]^{* * *}$} & {$[0.09]^{* *}$} \\
\hline N & & & & \\
R-squared & 196 & 196 & 196 & 196 \\
\hline \hline
\end{tabular}

Table III: Effect of NomCom gender composition on appointee gender - Excluding year 2014 appointees. In this table, we run our OLS specification on the sample of appointees excluding those from 2014. In all columns, Female $i t$ is 1 if probability that appointee $i$ is female exceeds $75 \%$, and $N_{o m C o m p}$ (resp., $X_{t}$ ) is the average of the "female dummies" among NomCom members (resp., volunteers). Post $t=1[$ Year $\geq 2012]$ for models (1) to (3); and $1[$ Year $\geq 2013]$ for model (4). Stars indicate significance at $* 10 \%, * * 5 \%$ and $* * * 1 \%$ level. Standard errors clustered by year.

To be clear, we do not argue that the 2014 procedural changes did not matter. Figure 2 shows that 2014 is actually a "peak" female appointment year. Our point is that the 2014 NomCom, on its own, does not explain why the causal impact of female representation on gender diversity changed sign in 2012 .

\section{Discussion and conclusions}

What prevents more women from being appointed to leadership roles in business organizations? One hypothesis is that women are under-represented within the formal groups, such as boards and promotion committees, that choose leaders. A second hypothesis is that the organizations as a whole might have failed to adopt norms and

\footnotetext{
${ }^{41}$ Table A.X reports the results obtained running Equation (2).
} 
values that promote gender diversity. We study a particular selectorate - the IETF Nominating Committee - whose members are randomly chosen. This randomness produces a natural experiment in female representation. We find that greater female representation in the selectorate causes more females to be appointed, but only after a change in IETF's informal and holistic norms.

Although we do not measure "informal norms" directly, we show that societal interest in the gender composition of STEM fields jumped around 2011-12 (as reflected in Google search terms); that this shift coincided with a sharp spike in discussion of diversity on IETF email lists; and that these broader shifts were reinforced by deliberate actions within the IETF (e.g., the creation of a Diversity Design Team, and the organic emergence of "codes of conduct"). Consistent with our interpretation, IETF's own diagnosis of the problem places a particular emphasis on culture:

"NomCom is itself a potentially diverse group of IETF participants, chosen at random from a pool of recent meeting attendees who offer their services. Hence, its problematic choices - or rather, omissions - could be seen as reflecting IETF culture generally." ${ }^{42}$

Our analysis of the IETF NomCom contributes to a prior literature on representation and selection for gender diversity that has produced mixed results. Well-designed causal studies of selectorates report conflicting and counterintuitive findings that suggest female representation both promotes and discourages the selection of women. For the first time, this paper documents a change in the sign of the relationship between representation and selection. This reversal does not reflect the availability of more female talent in the pipeline or changes to the formal selection procedures. Rather, it comes from a change in the informal and holistic norms and values that foster gender diversity, with support and encouragement from IETF leadership. These findings suggest that representation in the selectorate and "tone from the top" are both necessary to promote gender diversity in the selection of leaders.

\footnotetext{
${ }^{42}$ Crocker and Clark $(2015$, p. 3).
} 


\section{References}

Aidt, T. S., J. Dutta, And E. Loukoianova (2006): "Democracy comes to Europe: franchise extension and fiscal outcomes 1830-1938," European Economic Review, 50, 249-283.

Anwar, S., P. Bayer, And R. HJalmarsson (2012): "The impact of jury race in criminal trials," Quarterly Journal of Economics, 127, 1017-1055.

Arkko, J. (2013): "Diversity," IETF News, available at https://www.ietf .org/blog/ diversity/ (last accessed: December 16, 2020).

Bagues, M., M. Sylos-Labini, And N. Zinovyeva (2017): "Does the gender composition of scientific committees matter?" American Economic Review, 107, $1207-1238$.

Bagues, M. F. And B. Esteve-Volart (2010): "Can gender parity break the glass ceiling? Evidence from a repeated randomized experiment," Review of Economic Studies, 77, 1301-1328.

Berlinski, Samuel, T. D. And B. V. Coppenolle (2014): "Franchise Extension and the British Aristocracy," Legislative Studies Quarterly, 39, 531-558.

Bertrand, M., S. E. Black, S. Jensen, and A. Lleras-Muney (2019): "Breaking the glass ceiling? The effect of board quotas on female labour market outcomes in Norway," Review of Economic Studies, 86, 191-239.

Corvalan, A., P. Querubín, And S. Vicente (2020): "The political class and redistributive policies," Journal of the European Economic Association, 18, 1-48.

Crocker, D. And N. Clark (2015): "An IETF with Much Diversity and Professional Conduct," Request for Comments RFC 7704, Internet Engineering Task Force, Wilmington, DE.

De Paola, M. And V. Scoppa (2015): "Gender discrimination and evaluators' gender: Evidence from Italian academia," Economica, 82, 161-188.

Delgado-Pina, M. I., O. Rodriguez-Ruiz, A. Rodriguez-Duarte, and M. A. Sastre-Castillo (2020): "Gender Diversity in Spanish Banks: Trickle-Down and Productivity Effects," Sustainability, 12, 1-18.

Eastlake, D. (2004): "Publicly Verifiable Nominations Committee (NomCom) Random Selection," Request for Comments RFC 3797, Internet Engineering Task Force, Wilmington, DE.

Galvin, J. (2004): "IAB and IESG Selection, Confirmation, and Recall Process: Operation of the Nominating and Recall Committees," Request for Comments RFC 3777, Internet Engineering Task Force, Wilmington, DE. 
Gould, J. A., C. T. Kulik, And S. R. SArdeshmukh (2018a): "Gender diversity from the top: The trickle-down effect in the Australian public sector," Asia Pacific Journal of Human Resources, 56, 6-30.

(2018b): "Trickle-down effect: The impact of female board members on executive gender diversity," Human Resource Management, 57, 931-945.

Hoffman, P. And S. Harris (2006): "The Tao of IETF: A Novice's Guide to the Internet Engineering Task Force," Request for Comments RFC 4677, Internet Engineering Task Force, Wilmington, DE.

(2019): "The Tao of IETF: A Novice's Guide to the Internet Engineering Task Force," Available at https://www.ietf.org/tao.html (last accessed: December 16, 2020).

Huizer, E. AND D. Crocker (1994): "IETF Working Group: Guidelines and Procedures," Request for Comments RFC 1603, Internet Engineering Task Force, Wilmington, DE.

Kunze, A. AND A. R. Miller (2017): "Women helping women? Evidence from private sector data on workplace hierarchies," Review of Economics and Statistics, 99, 769-775.

LARCinese, V. (2014): "Enfranchisement and Representation: Evidence from the Introduction of Quasi-Universal Suffrage in Italy," Unpublished manuscript, London School of Economics and Political Science.

LotT, JR, J. R. And L. W. Kenny (1999): "Did women's suffrage change the size and scope of government?" Journal of Political Economy, 107, 1163-1198.

MaidA, A. And A. Weber (2020): "Female leadership and gender gap within firms: Evidence from an Italian board reform," ILR Review, in press.

Matsa, D. A. And A. R. Miller (2011): "Chipping away at the glass ceiling: Gender spillovers in corporate leadership," American Economic Review, 101, 635-639.

Miller, G. (2008): "Women's suffrage, political responsiveness, and child survival in American history," Quarterly Journal of Economics, 123, 1287-1327.

Moriarty, K. AND J. ARKko (2015): "IETF Diversity Update," IETF News, available at https://www.ietf.org/blog/ietf-diversity-update/ (last accessed: December 16, 2020).

Resnick, P. AND A. FARrel (2016): "IETF Anti-Harassment Procedures," Request for Comments RFC 7776, Internet Engineering Task Force, Wilmington, DE.

\begin{tabular}{|c|c|c|c|c|c|c|c|}
\hline \multirow{3}{*}{$\begin{array}{l}\text { TuRk, } \\
\text { Male' } \\
\text { available }\end{array}$} & \multirow{3}{*}{$\begin{array}{c}\text { V. } \\
\text { Culture }\end{array}$} & \multirow{3}{*}{$\begin{array}{c}(2015): \\
\text { at } \\
\text { at }\end{array}$} & & Memo & \multicolumn{2}{|c|}{ 'American, } & \\
\hline & & & & En & Task & & \\
\hline & & & & 8 & & & \\
\hline
\end{tabular}
memo-decries-american-white-male-culture-at-internet-engineering-task-force (last accessed: December 16, 2020).

Wais, K. (2016): "Gender Prediction Methods Based on First Names with genderizeR," The $R$ Journal, 8, 17-37. 


\section{Appendix: Supplementary Tables and Figures - Not for Publication}

\begin{tabular}{llc}
\hline \hline & Description & Year \\
\hline RTP & Real-time Transport Protocol & 2003 \\
SIP & Session Initiation Protocol & 2002 \\
HTTP & Hypertext Transfer Protocol & 1999 \\
IPV6 & Internet Protocol, Version 6 (IPv6) & 1998 \\
DHCP & Dynamic Host Configuration Protocol & 1997 \\
POP3 & Post Office Protocol - Version 3 & 1996 \\
NAT & Network Address Translator & 1994 \\
FTP & File Transfer Protocol & 1985 \\
TCP & Transmission Control Protocol & 1981 \\
IP & Internet Protocol & 1981 \\
\hline \hline
\end{tabular}

Table A.I: Examples of IETF Internet Standards. 


\begin{tabular}{|c|c|c|c|c|c|c|c|c|c|c|}
\hline & \multicolumn{10}{|c|}{ Panel A } \\
\hline & \multicolumn{5}{|c|}{ (1) } & \multicolumn{5}{|c|}{$(2)$} \\
\hline & \multicolumn{5}{|c|}{ NomCom Volunteers } & \multicolumn{5}{|c|}{ NomCom Members } \\
\hline & Mean & $\mathrm{SD}$ & Min & Max & $\mathrm{N}$ & Mean & $\mathrm{SD}$ & Min & Max & $\mathrm{N}$ \\
\hline \multirow[t]{5}{*}{1 [Individual is Female] } & 0.098 & 0.297 & 0 & 1 & 1,860 & 0.094 & 0.293 & 0 & 1 & 149 \\
\hline & \multicolumn{10}{|c|}{ Panel B } \\
\hline & \multicolumn{5}{|c|}{ (1) } & \multicolumn{5}{|c|}{$(2)$} \\
\hline & \multicolumn{5}{|c|}{ All IETF Participants } & \multicolumn{5}{|c|}{ All Appointees } \\
\hline & Mean & $\mathrm{SD}$ & Min & Max & $\mathrm{N}$ & Mean & $\mathrm{SD}$ & Min & $\operatorname{Max}$ & $\mathrm{N}$ \\
\hline 1 [Individual is Female] & 0.102 & 0.302 & 0 & 1 & 307,210 & 0.120 & 0.325 & 0 & 1 & 209 \\
\hline $\ln (1+\mathrm{RFCs})$ & 0.165 & 0.494 & 0 & 5.352 & 340,658 & 2.256 & 1.006 & 0 & 4.234 & 214 \\
\hline $\ln (1+$ Emails $)$ & 0.705 & 1.424 & 0 & 9.330 & 340,658 & 5.867 & 1.569 & 0 & 8.556 & 214 \\
\hline $\ln (1+$ Meetings $)$ & 1.123 & 0.693 & 0 & 4.304 & 340,658 & 3.289 & 0.493 & 1.792 & 4.111 & 214 \\
\hline
\end{tabular}

Table A.II: Summary statistics - NomCom Volunteers, NomCom Members, All IETF Participants and All Appointees. Panel A reports information on the share of female NomCom Volunteers (col. 1) and NomCom Members (col. 2). Panel B reports information on all the IETF participants (col. 1), and on the sample of All Appointees (col. 2). 1[Individual is Female] is 1 if probability that the individual in each subsample is female exceeds $75 \%$. Individuals whose gender could not be determined algorithmically are excluded from the sample. We also report information on the stock of published RFCs $(\ln (1+\mathrm{RFCs}))$, the number of emails sent to IETF listservs (ln(1+Emails)), and the number of IETF meetings attended by individual $i(\ln (1+$ Meetings $))$. 


\begin{tabular}{lcccc}
\hline \hline Specification & \multicolumn{4}{c}{ OLS } \\
Unit of Analysis & \multicolumn{4}{c}{ NomCom Appointee } \\
Outcome Variable & \multicolumn{4}{c}{1 Appointee is Female] } \\
& $(1)$ & $(2)$ & $(3)$ & $(4)$ \\
\hline \multirow{2}{*}{ Pre $\times$ NomCom Female Share } & 0.63 & -0.78 & -0.69 & -0.56 \\
& {$[0.84]$} & {$[0.25]^{* * *}$} & {$[0.25]^{* *}$} & {$[0.17]^{* * *}$} \\
Post $\times$ NomCom Female Share & & 2.17 & 2.36 & 2.64 \\
& & {$[0.70]^{* * *}$} & {$[0.61]^{* * *}$} & {$[0.88]^{* * *}$} \\
Pre $\times$ Volunteer Female Share & 0.89 & & -0.75 & -1.35 \\
& {$[1.66]$} & & {$[0.50]$} & {$[0.43]^{* * *}$} \\
Post $\times$ Volunteer Female Share & & & -3.57 & -4.01 \\
& & & {$[2.28]$} & {$[2.63]$} \\
Post & & -0.10 & 0.20 & 0.18 \\
& & {$[0.07]$} & {$[0.21]$} & {$[0.22]$} \\
\hline N & & & & \\
R-squared & 119 & 119 & 119 & 119 \\
\hline \hline
\end{tabular}

Table A.III: Effect of NomCom gender composition on appointee gender - ADs only. In this table, we look at the effect of NomCom gender composition on appointee gender considering the sample of ADs only. In all columns, Female $i$ is 1 if probability that appointee $i$ is female exceeds $75 \%$, and $N_{o m C o m p}$ (resp., $X_{t}$ ) is the average of the "female dummies" among NomCom members (resp., volunteers). Post Po $_{1}=1$ Year $\left.\geq 2012\right]$ for models (1) to (3); and $1[$ Year $\geq 2013]$ for model (4). Stars indicate significance at $* 10 \%, * * 5 \%$ and $* * * 1 \%$ level. Standard errors clustered by year. 


\begin{tabular}{|c|c|c|c|c|}
\hline \multirow{3}{*}{$\begin{array}{l}\text { Specification } \\
\text { Unit of Analysis } \\
\text { Outcome Variable }\end{array}$} & \multicolumn{4}{|c|}{$\overline{\mathrm{OLS}}$} \\
\hline & \multicolumn{4}{|c|}{$\operatorname{Pr}[$ Appointee is Female] } \\
\hline & (1) & (2) & (3) & (4) \\
\hline Pre $\times$ NomCom Female Share & 0.35 & -0.53 & -0.65 & -0.26 \\
\hline & {$[0.44]$} & {$[0.17]^{* * *}$} & {$[0.23]^{* *}$} & {$[0.25]$} \\
\hline Post $\times$ NomCom Female Share & & 1.03 & 1.13 & \\
\hline & & {$[0.32]^{* * *}$} & {$[0.20]^{* * *}$} & {$[0.29]^{* * *}$} \\
\hline Pre $\times$ Volunteer Female Share & 0.42 & & 0.81 & -0.78 \\
\hline & {$[1.00]$} & & {$[0.98]$} & {$[0.79]$} \\
\hline Post $\times$ Volunteer Female Share & & & -1.75 & -1.49 \\
\hline & & & {$[0.94]^{*}$} & {$[1.16]$} \\
\hline Post & & -0.06 & 0.15 & 0.08 \\
\hline & & {$[0.04]$} & {$[0.11]$} & {$[0.11]$} \\
\hline $\mathrm{N}$ & 214 & 214 & 214 & 214 \\
\hline R-squared & 0.01 & 0.04 & 0.04 & 0.04 \\
\hline
\end{tabular}

Table A.IV: Effect of NomCom gender composition on appointee gender Alternative gender imputation approach. In this table, we change the gender imputation approach from one based on a dummy that equals 1 if $\operatorname{Pr}$ [Appointee is Female] exceeds 75\%, to one based on raw probabilities obtained using genderizeR. Specifically, in all columns, Female $i_{i t}$ is the probability that appointee $i$ is female, and $N o m C o m p t$ (resp., $X_{t}$ ) is the average of the probabilities that NomCom members (resp., volunteers) are women. Post $t_{t}=1[$ Year $\geq 2012]$ for models (1) to (3); and $1[$ Year $\geq 2013]$ for model (4). Stars indicate significance at $* 10 \%$, $* * 5 \%$ and $* * * 1 \%$ level. Standard errors clustered by year. 


\begin{tabular}{lcccc}
\hline \hline Specification & \multicolumn{5}{c}{ Logistic (Average Marginal Effects) } \\
Unit of Analysis & \multicolumn{4}{c}{ NomCom Appointee } \\
Outcome Variable & \multicolumn{5}{c}{$1[$ Appointed is Female] } \\
& $(1)$ & $(2)$ & $(3)$ & $(4)$ \\
\hline \multirow{2}{*}{ Pre $\times$ NomCom Female Share } & 0.39 & -0.49 & -1.03 & -0.19 \\
& {$[0.45]$} & {$[0.16]^{* * *}$} & {$[0.59]^{*}$} & {$[0.21]^{*}$} \\
Post $\times$ NomCom Female Share & & 1.05 & 1.34 & 0.98 \\
& & {$[0.34]^{* * *}$} & {$[0.33]^{* * *}$} & {$[0.32]^{* * *}$} \\
Table 1 Controls & $\checkmark$ & $\checkmark$ & $\checkmark$ & $\checkmark$ \\
$\mathrm{N}$ & & & & $\checkmark$ \\
\hline \hline
\end{tabular}

Table A.V: Effect of NomCom gender composition on appointee gender - Logit specification. In all columns, Female $i t$ is 1 if probability that appointee $i$ is female exceeds $75 \%$, and NomComp $_{t}$ (resp., $X_{t}$ ) is the average of the "female dummies" among NomCom members (resp., volunteers). Post $t=1[$ Year $\geq 2012]$ for models (1) to (3); and 1[Year $\geq 2013]$ for model (4). The table reports average marginal effects (multiplied by 100 for legibility) and standard errors computed using the delta method. Table 1 controls refer to all explanatory variables shown in the corresponding column of Table I. Stars indicate significance at $* 10 \%$, $* * 5 \%$ and $* * * 1 \%$ level. Standard errors clustered by year. 


\begin{tabular}{lccc}
\hline \hline Specification & \multicolumn{3}{c}{ OLS } \\
Unit of Analysis & \multicolumn{3}{c}{ NomCom Appointee } \\
Outcome Variable & \multicolumn{2}{c}{1 Appointee is Female] } \\
& $(1)$ & $(2)$ & $(3)$ \\
\hline \multirow{2}{*}{ Pre $\times \Delta$ Female } & 0.33 & -0.60 & -0.14 \\
& {$[0.50]$} & {$[0.18]^{* * *}$} & {$[0.31]$} \\
Post $\times \Delta$ Female & & 1.23 & 1.00 \\
& & {$[0.26]^{* * *}$} & {$[0.40]^{* *}$} \\
Post & & 0.10 & 0.12 \\
& & {$[0.03]^{* * *}$} & {$[0.03]^{* * *}$} \\
\hline \multirow{3}{N}{} & 209 & 209 & 209 \\
R-squared & 0.00 & 0.05 & 0.04 \\
\hline \hline
\end{tabular}

Table A.VI: Effect of NomCom gender composition on appointee gender De-trended explanatory variable. In this table, we constrain $\beta_{j}=\gamma_{j}$ for $j=\{$ pre, post $\}$. In all columns, Female Fe $_{i t} 1$ if probability that appointee $i$ is female exceeds $75 \%$, and $\Delta$ Female $\equiv$ NomCom Female Share - Volunteer Female Share. Post $t_{t}=1[$ Year $\geq 2012]$ for models (1) to (3); and $1[$ Year $\geq 2013]$ for model (4). Stars indicate significance at $* 10 \%, * * 5 \%$ and $* * * 1 \%$ level. Standard errors clustered by year. 


\begin{tabular}{|c|c|c|c|c|}
\hline \multirow{2}{*}{$\begin{array}{l}\text { Specification } \\
\text { Unit of Analysis } \\
\text { Outcome Variable }\end{array}$} & \multicolumn{4}{|c|}{$\begin{array}{c}\text { OLS } \\
\text { IETF Participant-Year }\end{array}$} \\
\hline & $\begin{array}{l}1[\text { App } \\
(1)\end{array}$ & $\begin{array}{l}\text { ointed to Il } \\
\qquad(2)\end{array}$ & $\begin{array}{l}\text { SG or IAB } \\
(3)\end{array}$ & $\times 100$ \\
\hline Pre $\times$ Female $\times$ NomCom Share & $\begin{array}{c}0.30 \\
{[0.34]}\end{array}$ & $\begin{array}{c}-0.37 \\
{[0.15]^{* *}}\end{array}$ & $\begin{array}{c}-0.36 \\
{[0.15]^{* *}}\end{array}$ & $\begin{array}{c}-0.33 \\
{[0.15]^{* *}}\end{array}$ \\
\hline Post $\times$ Female $\times$ NomCom Share & & $\begin{array}{c}0.78 \\
{[0.26]^{* * *}}\end{array}$ & $\begin{array}{c}0.77 \\
{[0.26]^{* * *}}\end{array}$ & $\begin{array}{c}0.78 \\
{[0.24]^{* * *}}\end{array}$ \\
\hline Pre $\times$ Female & $\begin{array}{l}-0.02 \\
{[0.02]}\end{array}$ & $\begin{array}{l}-0.00 \\
{[0.01]}\end{array}$ & $\begin{array}{c}0.01 \\
{[0.01]}\end{array}$ & $\begin{array}{c}0.00 \\
{[0.01]}\end{array}$ \\
\hline Post $\times$ Female & & $\begin{array}{l}-0.03 \\
{[0.03]}\end{array}$ & $\begin{array}{l}-0.01 \\
{[0.03]}\end{array}$ & $\begin{array}{l}-0.03 \\
{[0.02]}\end{array}$ \\
\hline $\ln (1+\mathrm{RFCs})$ & & & $\begin{array}{c}0.23 \\
{[0.03]^{* * *}}\end{array}$ & $\begin{array}{c}0.03 \\
{[0.02]}\end{array}$ \\
\hline $\ln (1+$ Emails $)$ & & & $\begin{array}{c}0.04 \\
{[0.01]^{* * *}}\end{array}$ & $\begin{array}{c}0.01 \\
{[0.01]}\end{array}$ \\
\hline $\ln (1+$ Meetings $)$ & & & $\begin{array}{c}0.04 \\
{[0.01]^{* * *}}\end{array}$ & $\begin{array}{c}0.02 \\
{[0.01]^{* * *}}\end{array}$ \\
\hline Incumbent & & & & $\begin{array}{c}0.34 \\
{[0.06]^{* * *}}\end{array}$ \\
\hline $\begin{array}{l}\text { WG Chair Experience Effects } \\
\text { Year Fixed Effects }\end{array}$ & $\checkmark$ & $\checkmark$ & $\checkmark$ & $\begin{array}{l}\checkmark \\
\checkmark\end{array}$ \\
\hline $\begin{array}{l}\mathrm{N} \\
\mathrm{R} \text {-squared }\end{array}$ & $\begin{array}{c}307,210 \\
0.00\end{array}$ & $\begin{array}{l}307,210 \\
0.00\end{array}$ & $\begin{array}{c}307,210 \\
0.01\end{array}$ & $\begin{array}{c}307,210 \\
0.03\end{array}$ \\
\hline
\end{tabular}

Table A.VII: Effect of NomCom gender composition on appointments controlling for individual experience - ADs only. In this table, we look at the effect of NomCom gender composition on appointee gender considering the sample of ADs only. In all columns Female is 1 if probability that individual $i$ is female exceeds $75 \%$, and $N o m C o m p_{t}$ is the average of the "female dummies" among NomCom members. Post $t=1[$ Year $\geq 2012]$ for models (1) to (3); and $1[$ Year $\geq 2013]$ for model (4). Stars indicate significance at $* 10 \%, * * 5 \%$ and $* * * 1 \%$ level. Standard errors clustered by year. 


\begin{tabular}{|c|c|c|c|c|}
\hline \multirow{2}{*}{$\begin{array}{l}\text { Specification } \\
\text { Unit of Analysis } \\
\text { Outcome Variable }\end{array}$} & \multicolumn{4}{|c|}{$\begin{array}{c}\text { OLS } \\
\text { IETF Participant-Year }\end{array}$} \\
\hline & \multicolumn{4}{|c|}{$\begin{array}{l}\operatorname{Pr}[\text { Appointed to IESG or IAB }] \times 100 \\
(1)\end{array}$} \\
\hline Pre $\times$ Female $\times$ NomCom Share & $\begin{array}{c}0.28 \\
{[0.29]}\end{array}$ & $\begin{array}{c}-0.33 \\
{[0.13]^{* *}}\end{array}$ & $\begin{array}{c}-0.29 \\
{[0.12]^{* *}}\end{array}$ & $\begin{array}{c}-0.24 \\
{[0.09]^{* *}}\end{array}$ \\
\hline Post $\times$ Female $\times$ NomCom Share & & $\begin{array}{c}0.71 \\
{[0.23]^{* * *}}\end{array}$ & $\begin{array}{c}0.71 \\
{[0.24]^{* * *}}\end{array}$ & $\begin{array}{c}0.76 \\
{[0.22]^{* * *}}\end{array}$ \\
\hline Pre $\times$ Female & $\begin{array}{l}-0.02 \\
{[0.02]}\end{array}$ & $\begin{array}{l}-0.00 \\
{[0.02]}\end{array}$ & $\begin{array}{c}0.03 \\
{[0.02]^{*}}\end{array}$ & $\begin{array}{c}0.01 \\
{[0.02]}\end{array}$ \\
\hline Post $\times$ Female & & $\begin{array}{l}-0.04 \\
{[0.03]}\end{array}$ & $\begin{array}{c}0.01 \\
{[0.03]}\end{array}$ & $\begin{array}{l}-0.02 \\
{[0.03]}\end{array}$ \\
\hline $\ln (1+\mathrm{RFCs})$ & & & $\begin{array}{c}0.38 \\
{[0.05]^{* * *}}\end{array}$ & $\begin{array}{c}0.05 \\
{[0.04]}\end{array}$ \\
\hline $\ln (1+$ Emails $)$ & & & $\begin{array}{c}0.07 \\
{[0.01]^{* * *}}\end{array}$ & $\begin{array}{c}0.02 \\
{[0.01]^{* *}}\end{array}$ \\
\hline $\ln (1+$ Meetings $)$ & & & $\begin{array}{c}0.06 \\
{[0.01]^{* * *}}\end{array}$ & $\begin{array}{c}0.03 \\
{[0.01]^{* * *}}\end{array}$ \\
\hline Incumbent & & & & $\begin{array}{c}0.54 \\
{[0.08]^{* * *}}\end{array}$ \\
\hline $\begin{array}{l}\text { WG Chair Experience Effects } \\
\text { Year Fixed Effects }\end{array}$ & $\checkmark$ & $\checkmark$ & $\checkmark$ & $\begin{array}{l}\checkmark \\
\checkmark\end{array}$ \\
\hline $\begin{array}{l}\mathrm{N} \\
\mathrm{R} \text {-squared }\end{array}$ & $\begin{array}{c}328,602 \\
0.00\end{array}$ & $\begin{array}{c}328,602 \\
0.00\end{array}$ & $\begin{array}{c}328,602 \\
0.01\end{array}$ & $\begin{array}{c}328,602 \\
0.04\end{array}$ \\
\hline
\end{tabular}

Table A.VIII: Effect of NomCom gender composition on appointments controlling for individual experience - Alternative gender imputation approach. In this table, we change the gender imputation approach from one based on a dummy that equals 1 if $\operatorname{Pr}$ [Appointee is Female] exceeds $75 \%$, to one based on raw probabilities obtained using genderize $R$. Specifically, in all columns Female $_{i}$ is the probability that individual $i$ is female, and NomComp is the average of the probabilities that NomCom members are women. Post $_{t}=1[$ Year $\geq 2012]$ for models (1) to (3); and 1[Year $\left.\geq 2013\right]$ for model (4). Stars indicate significance at ${ }^{*} 10 \%,{ }^{*} 5 \%$ and ${ }^{* * *} 1 \%$ level. Standard errors clustered by year. 


\begin{tabular}{|c|c|c|c|c|}
\hline $\begin{array}{l}\text { Specification } \\
\text { Unit of Analysis }\end{array}$ & \multicolumn{4}{|c|}{$\begin{array}{c}\text { Logistic (Average Marginal Effects) } \\
\text { IETF Participant-Year }\end{array}$} \\
\hline \multirow[t]{2}{*}{ Outcome Variable } & \multicolumn{4}{|c|}{ 1[Appointed to IESG or IAB] } \\
\hline & (1) & (2) & (3) & (4) \\
\hline Pre $\times$ Female $\times$ NomCom Share & $\begin{array}{c}0.25 \\
{[0.16]}\end{array}$ & $\begin{array}{c}-0.63 \\
{[0.33]^{*}}\end{array}$ & $\begin{array}{c}-0.89 \\
{[0.47]^{*}}\end{array}$ & $\begin{array}{c}-0.76 \\
{[0.41]^{*}}\end{array}$ \\
\hline Post $\times$ Female $\times$ NomCom Share & & $\begin{array}{c}0.42 \\
{[0.07]^{* * *}}\end{array}$ & $\begin{array}{c}0.69 \\
{[0.11]^{* * *}}\end{array}$ & $\begin{array}{c}0.58 \\
{[0.11]^{* * *}}\end{array}$ \\
\hline $\begin{array}{l}\text { Table } 2 \text { Controls } \\
\text { WG Chair Fxnerience Effec }\end{array}$ & $\checkmark$ & $\checkmark$ & $\checkmark$ & $\checkmark$ \\
\hline Year Fixed Effects & $\checkmark$ & $\checkmark$ & $\checkmark$ & $\checkmark$ \\
\hline $\mathrm{N}$ & 328,602 & 328,602 & 328,602 & 328,602 \\
\hline
\end{tabular}

Table A.IX: Effect of NomCom gender composition on appointments controlling for individual experience - Logit specification. In all columns Female ${ }_{i}$ is the probability that individual $i$ is female, and NomComp $p_{t}$ is the average of the probabilities that NomCom members are women. Post $_{t}=1[$ Year $\geq 2012]$ for models (1) to (3); and 1[Year $\left.\geq 2013\right]$ for model (4). The table reports average marginal effects (multiplied by 100 for legibility) and standard errors computed using the delta method. Table 2 controls refer to all explanatory variables shown in the corresponding column of Table II. Stars indicate significance at ${ }^{*} 10 \%,{ }^{*} 5 \%$ and ${ }^{* * *} 1 \%$ level. Standard errors clustered by year. 


\begin{tabular}{|c|c|c|c|c|}
\hline \multirow{2}{*}{$\begin{array}{l}\text { Specification } \\
\text { Unit of Analysis } \\
\text { Outcome Variable }\end{array}$} & \multicolumn{4}{|c|}{$\begin{array}{c}\text { OLS } \\
\text { IETF Participant-Year }\end{array}$} \\
\hline & $\begin{array}{l}1[\text { App } \\
(1)\end{array}$ & $\begin{array}{l}\text { inted to I } \\
\quad(2)\end{array}$ & $\begin{array}{l}\text { ESG or IAI } \\
(3)\end{array}$ & 3] $\times 100$ \\
\hline Pre $\times$ Female $\times$ NomCom Share & $\begin{array}{c}0.27 \\
{[0.32]}\end{array}$ & $\begin{array}{c}-0.29 \\
{[0.14]^{*}}\end{array}$ & $\begin{array}{c}-0.26 \\
{[0.13]^{*}}\end{array}$ & $\begin{array}{c}-0.22 \\
{[0.11]^{*}}\end{array}$ \\
\hline Post $\times$ Female $\times$ NomCom Share & & $\begin{array}{c}0.67 \\
{[0.30]^{* *}}\end{array}$ & $\begin{array}{c}0.67 \\
{[0.31]^{* *}}\end{array}$ & $\begin{array}{c}0.67 \\
{[0.25]^{* *}}\end{array}$ \\
\hline Pre $\times$ Female & $\begin{array}{l}-0.02 \\
{[0.03]}\end{array}$ & $\begin{array}{l}-0.00 \\
{[0.02]}\end{array}$ & $\begin{array}{c}0.02 \\
{[0.02]}\end{array}$ & $\begin{array}{c}0.01 \\
{[0.02]}\end{array}$ \\
\hline Post $\times$ Female & & $\begin{array}{l}-0.04 \\
{[0.03]}\end{array}$ & $\begin{array}{c}0.00 \\
{[0.04]}\end{array}$ & $\begin{array}{l}-0.03 \\
{[0.03]}\end{array}$ \\
\hline $\ln (1+\mathrm{RFCs})$ & & & $\begin{array}{c}0.40 \\
{[0.05]^{* * *}}\end{array}$ & $\begin{array}{c}0.06 \\
{[0.04]}\end{array}$ \\
\hline $\ln (1+$ Emails $)$ & & & $\begin{array}{c}0.07 \\
{[0.01]^{* * *}}\end{array}$ & $\begin{array}{c}0.02 \\
{[0.01]^{* *}}\end{array}$ \\
\hline $\ln (1+$ Meetings $)$ & & & $\begin{array}{c}0.06 \\
{[0.01]^{* * *}}\end{array}$ & $\begin{array}{c}0.03 \\
{[0.01]^{* * *}}\end{array}$ \\
\hline Incumbent & & & & $\begin{array}{c}0.58 \\
{[0.09]^{* * *}}\end{array}$ \\
\hline $\begin{array}{l}\text { WG Chair Experience Effects } \\
\text { Year Fixed Effects }\end{array}$ & $\checkmark$ & $\checkmark$ & $\checkmark$ & $\begin{array}{l}\checkmark \\
\checkmark\end{array}$ \\
\hline $\begin{array}{l}\mathrm{N} \\
\mathrm{R} \text {-squared }\end{array}$ & $\begin{array}{c}287,348 \\
0.00\end{array}$ & $\begin{array}{c}287,348 \\
0.00\end{array}$ & $\begin{array}{c}287,348 \\
0.01\end{array}$ & $\begin{array}{c}287,348 \\
0.04\end{array}$ \\
\hline
\end{tabular}

Table A.X: Effect of NomCom gender composition on appointments controlling for individual experience - Excluding year 2014 appointees. In this table, we run our OLS specification on the sample of IETF participants excluding those from 2014. In all columns Female $_{i}$ is 1 if probability that individual $i$ is female exceeds $75 \%$, and NomComp $_{t}$ is the average of the "female dummies" among NomCom members. Post $t_{t}=1[$ Year $\geq 2012]$ for models (1) to (3); and $1[$ Year $\geq 2013]$ for model (4). Stars indicate significance at $* 10 \%, * * 5 \%$ and $* * * 1 \%$ level. Standard errors clustered by year. 


\begin{tabular}{lccc}
\hline \hline & $(1)$ & $(2)$ & $(2)$ \\
& $\begin{array}{c}\text { Share Female } \\
\text { NomCom Members }\end{array}$ & $\begin{array}{c}\text { Share Female } \\
\text { NomCom Volunteers }\end{array}$ & $\begin{array}{c}\text { Share Female } \\
\text { IETF Participant }\end{array}$ \\
\hline NomCom Year & -0.00 & 0.00 & 0.00 \\
& {$[0.00]$} & {$[0.00]$} & {$[0.00]^{* * *}$} \\
\hline N & 16 & 16 & 16 \\
R-squared & 0.03 & 0.30 & 0.81 \\
\hline \hline
\end{tabular}

Table A.XI: No time trend in percentage of women in the samples of NomCom Members (col. 1), NomCom Volunteers (col. 2) and IETF Participants (col. 3). 


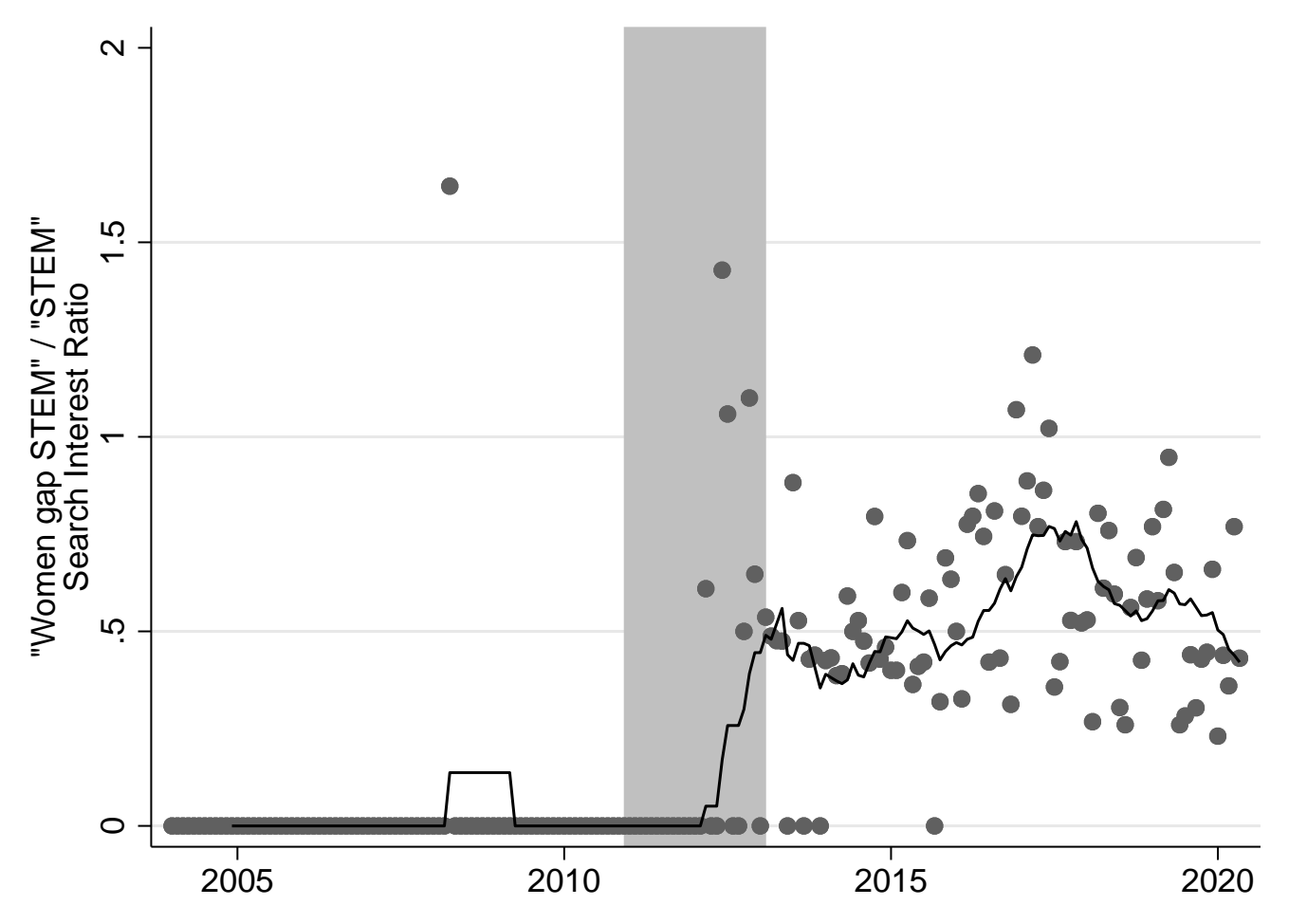

Figure A.1: Societal norms change in calendar year 2011-12. Each point corresponds to the monthly ratio of the search-interest value for "women gap STEM" over the search-interest value of "STEM." The solid line is a 12 month trailing average, and the shaded area covers calendar years 2011-12. Source: Google Trends. 

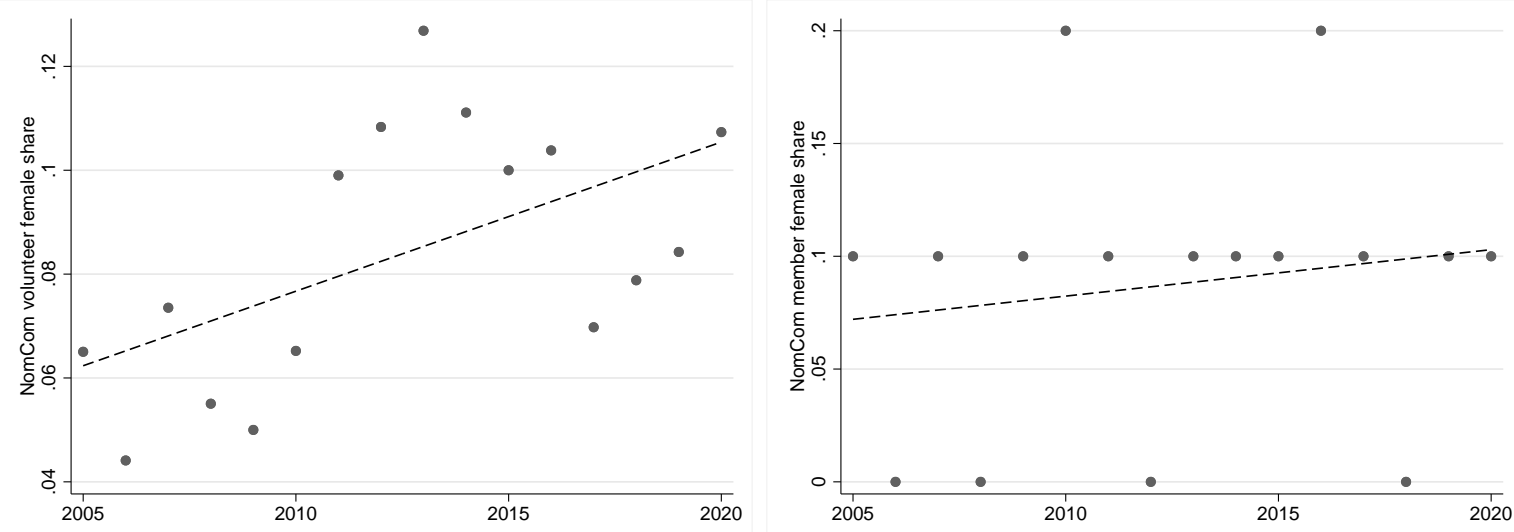

Figure A.2: NomCom female volunteers and members. The horizontal axis in every graph is NomCom year, which coincides with the calendar year in which a given NomCom makes appointments. The left panel is the share of women among all NomCom volunteers (volunteers must be NomCom-eligible). The right panel is the share of women among all NomCom members. Individuals whose gender could not be determined algorithmically are excluded from the sample. Comparing the left panel with Figure 2 indicates a pattern of non-decreasing female presence in the pool of "appointables" during the years 2005-2011(as proxied by NomCom volunteering), but a decreasing appointment rate. 


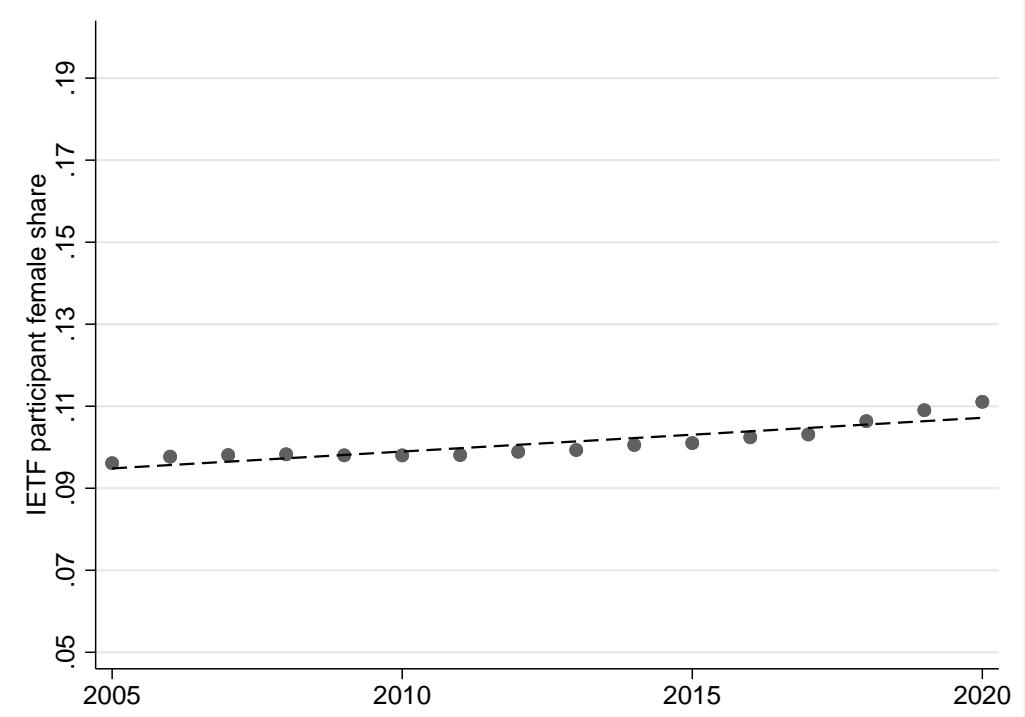

Figure A.3: Share of female IETF participants. The vertical axes represent the fraction of women among IETF participants, based on the coding of gender described in the text. On the horizontal axis is the calendar year. Individuals whose gender could not be determined algorithmically are excluded from the sample. 